\title{
Correlation of central visual function and ROP risk factors in prematures with and without acute ROP at the age of 6-13 years: the Giessen long-term ROP study
}

\author{
W Bowl, B Lorenz, K Stieger, S Schweinfurth, K Holve, C Friedburg, \\ M Andrassi-Darida
}

Department of Ophthalmology, Justus-Liebig-University, Giessen, Germany

\section{Correspondence to} Professor B Lorenz, Department of Ophthalmology, Justus-Liebig-University, Friedrichstrasse 18, Giessen 35392, Germany: birgit.lorenz@uniklinikumgiessen.de

Received 18 September 2015 Revised 26 October 2015 Accepted 31 October 2015 Published Online First 1 December 2015

\section{CrossMark}

To cite: Bowl W, Lorenz $B$ Stieger $\mathrm{K}$, et al. Br J Ophthalmol

2016;100:1238-1244.

\section{ABSTRACT}

Aim To correlate light increment sensitivity (LIS) and visual acuity (VA) with birth weight (BW), gestational age (GA) and stage of acute retinopathy of prematurity (ROP) (STG) in premature children at school age.

Methods 180 children (150 former prematures and 30 age-matched term-born children) were enrolled at age 6-13 years. Former prematures were categorised by the results of the initial ROP screening based on digital wide-field fundus imaging: absence of ROP $(n=100)$ and spontaneously resolved ROP $(n=50)$. The latter group was further subdivided according to their STG (Stg 1; Stg 2; Stg 3). Both groups were categorised into sectors by BW (<1000 g; 1000-1500 g; >1500 g), and GA ( $\leq 28$ weeks; $>28<32$ weeks; $\geq 32$ weeks). VA was assessed with Early Treatment of Diabetic Retinopathy Study letters, LIS was measured at $0^{\circ}, 2.8^{\circ}$ and $8^{\circ}$ in the visual field (Microperimeter MP1, Nidek Technologies), and spherical equivalent refraction assessed with a Nidek autorefractor (Nidek, Italy).

Results Central and pericentral LIS $\left(0^{\circ}\right.$ and $\left.2.8^{\circ}\right)$ and VA were significantly lower in all groups and sectors compared with term-born controls except for BW $>1500 \mathrm{~g}$ for LIS and GA $>28$ to $<32 \mathrm{~W}$ for VA. No significant differences were found for LIS at $8^{\circ}$ in all groups. No correlation was found between LIS and VA on an individual basis.

Conclusions Low BW, GA and increasing severity of spontaneously resolving ROP were associated with significantly decreased central visual function. In addition to VA, LIS measurement further describes foveal function and is a unique parameter to assess parafoveal function.

\section{INTRODUCTION}

Neonatal intensive care has improved dramatically over the last 30 years, leading to increased survival rates of preterm infants and even of those with birth weights (BWs) $<1000$ g. ${ }^{1}$ The immature state of the retina at birth in these extremely preterm infants often results in an altered foveal morphology. ${ }^{2-4}$ It remains unclear how long it lasts until the foveal region reaches maturity and which factors may prohibit complete foveal maturation in extremely premature infants over time. ${ }^{5-8}$

Retinopathy of prematurity (ROP) is a typical complication in very preterm infants with a multifactorial pathogenesis that is tightly related to the immaturity of the organ system. ${ }^{9-11}$ Major risk factors for ROP include low gestational age (GA) at birth $^{10}$ and low BWs. ${ }^{11}$ International committees have developed standardised classification systems, such as the International Classification of Retinopathy of Prematurity in 1984, which was revised in $2005,{ }^{12}{ }^{13}$ and the Early Treatment of Retinopathy of Prematurity (ETROP) guidelines. ${ }^{14}$

Long-term functional consequences of prematurity of the retina alone or the presence of ROP have been analysed in several large studies, for example, in a large population-based study in Sweden, ${ }^{15-19}$ in the Cryotherapy for Retinopathy of Prematurity Study (CRYOROP) study ${ }^{20}{ }^{21}$ or in the ETROP study. ${ }^{22-24}$ Classic read-out parameters are visual acuity (VA) and the prevalence of high refractive errors, strabismus and amblyopia. Often, low BW and GA as well as increasing severity of ROP are risk factors for an unfavourable ocular outcome for these parameters. ${ }^{25-33}$

However, all these parameters describe the function of photoreceptors in the centre of the fovea but do not allow retrieval of functional information about parafoveal or more peripheral photoreceptors. With the advent of early retinal morphological data in premature infants with and without ROP seen with spectral domain optical coherence tomography (SD-OCT), this kind of information becomes increasingly interesting. ${ }^{34}{ }^{35}$ Fundus-controlled perimetry provides a measurement of the light increment sensitivity (LIS) at defined loci within a $25^{\circ}$ visual field and has allowed to detect small deficits in visual function in the parafoveal and macular area in other patient cohorts. ${ }^{36} 37$

The present study was launched in 2011 in order to investigate the long-term functional and morphological outcome in former preterm infants with well-characterised retinal morphology at time of initial ROP screening. Here, we present the results of the functional analysis of the central retina (LIS, VA) at school age and correlated them with ROP risk factors at birth and presence of ROP at time of initial ROP screening. For the first time in a large cohort study of former premature infants, funduscontrolled perimetry data reveal functional information not only within the foveal centre but also in adjacent parafoveal and macular areas.

\section{METHODS}

Patients

The present study is a long-term follow-up study of prematurely born participants from a multicentre field study between 2001 and $2007 .^{38}$ All children included in the present study were imaged at the 
time of the ROP screening by digital wide-field retinal imaging (RetCam I, Massie Lab, California, USA), which provides objective documentation of an eventual ROP. In the present study, only children without apparent psychological or neuronal disorders, neonatological hypoglycaemia, intraventricular haemorrhage or severe birth asphyxia-related hypoxic ischaemic encephalopathy were included, and all children attended regular schools and showed no significant deficiencies in basic literacy and numeracy. Parents were also specifically asked as to early childhood development and performance at school. All perinatal
Stimulus pattern

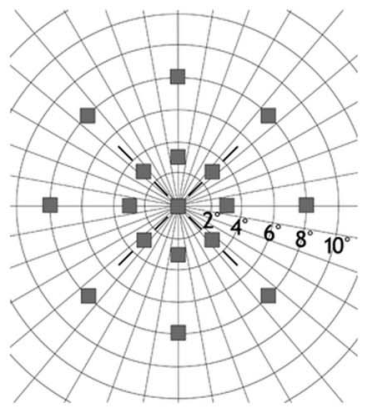

C

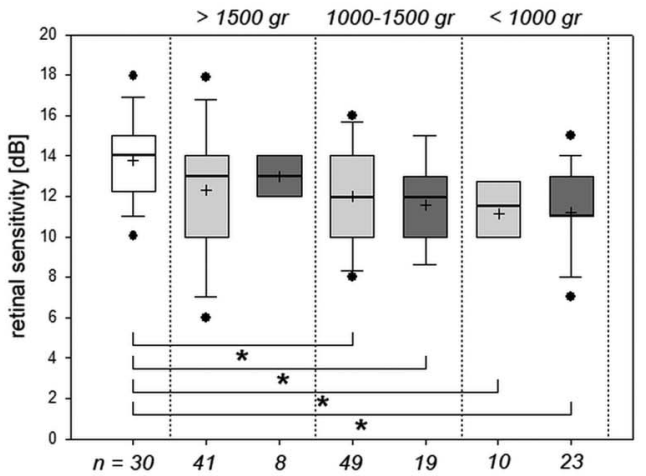

E

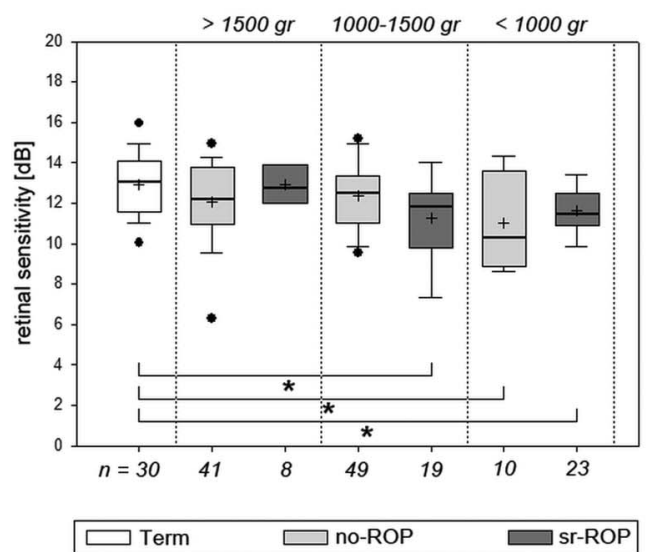

data and digital fundus images were available from the original field study. ${ }^{38}$

Healthy age-matched subjects were recruited from the local population, who had no history of ocular abnormalities, strabismus, amblyopia or high refractive errors, and who were capable of performing all tests in this study.

\section{Fundus-controlled perimetry}

The MP1 images the fundus in real time with an infrared fundus camera and allows with an automated tracking system

B LIS with Goldmann I stimuli in Microperimetry

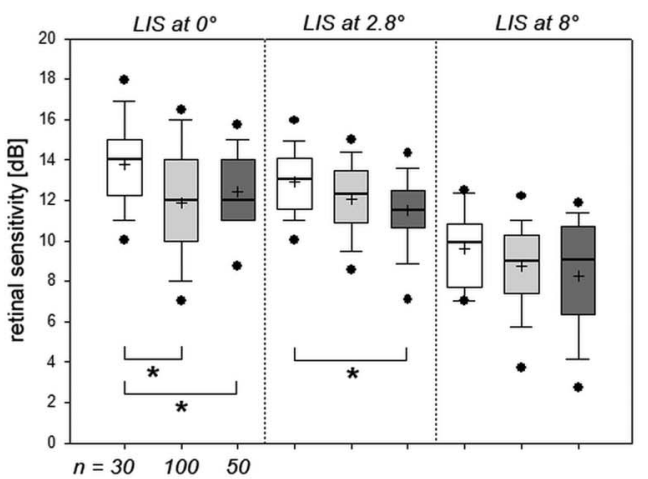

D

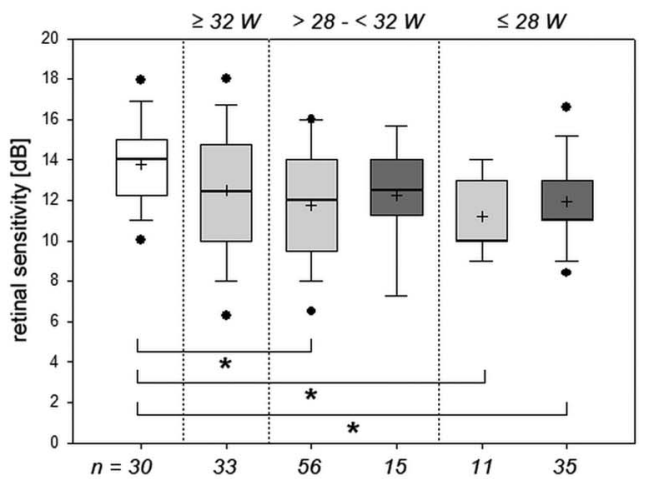

$\mathrm{F}$

Pericentral $\left(2.8^{\circ}\right)$ LIS divided by GA

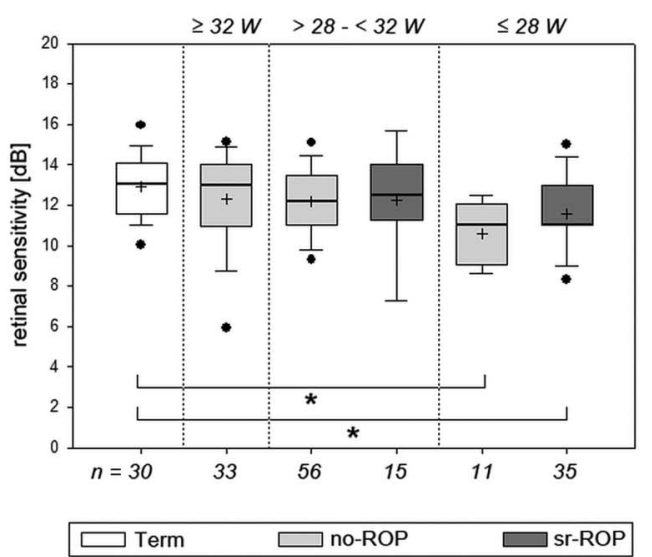

Figure 1 Light increment sensitivity (LIS) data. (A) Stimulus pattern of the data points in the visual field at $0^{\circ}, 2.8^{\circ}$ and $8^{\circ}$ eccentricity. All points of a given eccentricity ( $n=8)$ were added up to get a medium value and SD. (B) LIS data for the different study groups at $0^{\circ}, 2.8^{\circ}$ and $8^{\circ}$ eccentricity. (C and D) Correlation of LIS with birth weight $(\mathrm{BW})$ at central $\left(0^{\circ}, \mathrm{C}\right)$ and pericentral $\left(2.8^{\circ}, \mathrm{D}\right)$ location. (E and F) Correlation of LIS with gestational age (GA) at central $\left(0^{\circ}, \mathrm{E}\right)$ and pericentral $\left(2.8^{\circ}, \mathrm{F}\right)$ location. Significant correlations are marked $\left({ }^{*}\right.$ corresponds to $\left.\mathrm{p}<0.05\right)$, all other combinations corresponds to $\mathrm{p}>0.05$. no-ROP, without resolved retinopathy of prematurity; sr-ROP, spontaneously resolved retinopathy of prematurity; Term, term-born children. 
Table 1 Demographic data of the study participants

\begin{tabular}{|c|c|c|c|c|c|c|}
\hline Group & $\mathbf{n}$ & Age (years) (median) & $\operatorname{Sex}(m / f)$ & Birth weight $(g)( \pm S D)$ & Gestational age (weeks) $( \pm$ SD) & SER (Dpt) $( \pm S D)$ \\
\hline Term & 30 & $6-12(9)$ & $12 / 18$ & $3488( \pm 294)$ & $39.8( \pm 1)$ & $0.12( \pm 0.65)$ \\
\hline No-ROP & 100 & $7-13(10)$ & $54 / 46$ & $1497( \pm 389)$ & $30.7( \pm 2.3)$ & $0.43( \pm 2.66)$ \\
\hline$<1000 \mathrm{~g}$ & 10 & $7-12(10)$ & $6 / 4$ & $917( \pm 80)$ & $28.2( \pm 2.0)$ & $1.02( \pm 3.90)$ \\
\hline $1000-1500 \mathrm{~g}$ & 49 & $7-13(10)$ & $24 / 25$ & $1299( \pm 124)$ & $30.0( \pm 1.9)$ & $0.43( \pm 2.24)$ \\
\hline$>1500 \mathrm{~g}$ & 41 & $7-12(10)$ & $24 / 17$ & $1857( \pm 289)$ & $32.1( \pm 2.2)$ & $0.26( \pm 2.71)$ \\
\hline$\leq 28$ weeks & 11 & $9-13(10)$ & $6 / 5$ & $1061( \pm 244)$ & $27.2( \pm 0.6)$ & $0.78( \pm 4.24)$ \\
\hline$>28-<32$ weeks & 56 & $7-13(10)$ & $33 / 23$ & $1441( \pm 257)$ & $30( \pm 0.7)$ & $0.38( \pm 2.67)$ \\
\hline$\geq 32$ weeks & 33 & $7-12(10)$ & $15 / 18$ & $1730( \pm 423)$ & $33.6( \pm 1.5)$ & $0.42( \pm 1.99)$ \\
\hline$s r-R O P$ & 50 & $7-12(9)$ & $29 / 21$ & $1056( \pm 204)$ & $27.8( \pm 1.8)$ & $0.74( \pm 1.88)$ \\
\hline$<1000 \mathrm{~g}$ & 23 & $7-12(9.1)$ & $11 / 12$ & $789( \pm 83)$ & $26.3( \pm 0.8)$ & $0.93( \pm 1.99)$ \\
\hline $1000-1500 \mathrm{~g}$ & 19 & $7-12(8.8)$ & $12 / 7$ & $1222( \pm 101)$ & $29.1( \pm 1.1)$ & $1.19( \pm 2.13)$ \\
\hline$>1500 \mathrm{~g}$ & 8 & $7-12(9)$ & $6 / 2$ & $1618( \pm 105)$ & $29.8( \pm 2.2)$ & $-1.55( \pm 2.23)$ \\
\hline$\leq 28$ weeks & 35 & $7-12(9.2)$ & $18 / 17$ & $931( \pm 93)$ & $26.3( \pm 0.9)$ & $1.14( \pm 1.75)$ \\
\hline$>28-<32$ weeks & 15 & $7-12(8.9)$ & $11 / 4$ & $1292( \pm 128)$ & $29.8( \pm 1.5)$ & $0.70( \pm 2.14)$ \\
\hline$\geq 32$ weeks & 0 & - & - & - & - & - \\
\hline Stg 1 & 21 & $7-12(9.1)$ & $12 / 9$ & $1233( \pm 136)$ & $28.3( \pm 1.7)$ & $1.12( \pm 2.33)$ \\
\hline $\operatorname{stg} 2$ & 21 & $7-12(8.9)$ & $12 / 9$ & $938( \pm 87)$ & $27.5( \pm 0.9)$ & $1.07( \pm 2.10)$ \\
\hline Stg 3 & 8 & $7-12(9.2)$ & $5 / 3$ & $883( \pm 102)$ & $27.0( \pm 0.4)$ & $0.7( \pm 2.02)$ \\
\hline
\end{tabular}

No-ROP, without resolved retinopathy of prematurity; sr-ROP, spontaneously resolved ROP; SER (Dpt), spherical equivalent of refraction in diopters.

compensating for eye movement during examination. Fixation target and stimuli appear on a liquid crystal display within the MP1 and are imaged back along the same optical path onto the retina. For all conditions, background luminance was $1.27 \mathrm{~cd} / \mathrm{m}^{2}$. Test targets could be attenuated in steps of $1 \mathrm{~dB}(0.1 \mathrm{log})$ from maximum brightness $\left(127 \mathrm{~cd} / \mathrm{m}^{2}\right.$, defined as $0 \mathrm{~dB}$ for white) down to $20 \mathrm{~dB}$, that is, the background luminance. Refractive errors were compensated within the system of the instrument.

Stimuli were presented in a slightly darkened room to the better seeing eye at 17 positions of a customised pattern covering the posterior pole of the retina up to $8^{\circ}$ eccentricity (figure $1 \mathrm{~A}$ ). The pupil was left undilated. LIS thresholds were determined with a 4-2 staircase strategy. Results of the left eye were mirrored along the vertical axis to be comparable to those of the right eye.

LIS divided by Stage of ROP

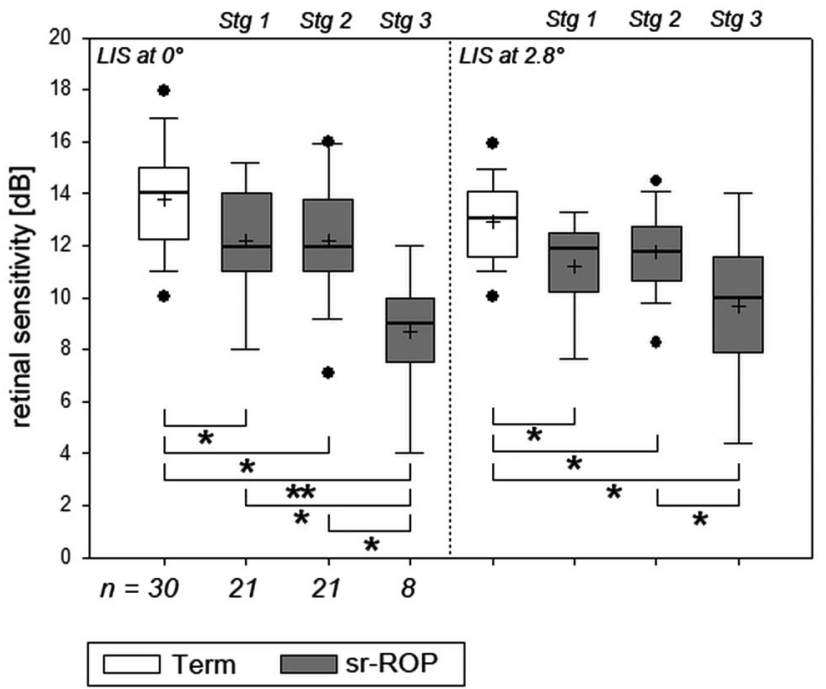

Figure 2 Correlation of light increment sensitivity (LIS) with stage of retinopathy of prematurity (ROP). Significant correlations are marked ( ${ }^{*}$ corresponds to $p<0.05$ ), all other combinations corresponds to $\mathrm{p}>0.05$. sr-ROP, spontaneously resolved retinopathy of prematurity; Term, term-born children.
Subjects were asked to fixate a custom-made red X, $10^{\circ}$ in diameter (figure 1A). Gaps within the $\mathrm{X}$ allow projecting stimuli in the centre of fixation or at parafoveal positions without interfering with the fixation target. Initially, fixation stability derived from tracking was continuously recorded for $5 \mathrm{~s}$. Thereafter, fixation was recorded during stimulus presentation and mapped. The examination started always with stimuli-sized Goldmann III (25.7 min of arc), followed by a second examination with stimulisized Goldmann I (6.45 min of arc) according to ref. 36 Because of the ceiling effect in measurements with Goldmann III stimuli, testing this stimulus size was used for training and familiarisation with the test. Only Goldmann I stimuli provided reliable LIS thresholds. ${ }^{36}$ The examination was repeated if the false positive answers (optic-nerve head tests) reached a critical limit of $50 \%$.

\section{Visual acuity}

The Early Treatment of Diabetic Retinopathy Study acuity charts were used to assess VA throughout the study. ${ }^{39}$ Only one eye that provided the best results from each participant was included. Landolt $\mathrm{C}$ ring testing (a standardised procedure following the EN ISO 8596 norm) was used as internal control. Refractive data were assessed with a Nidek Autorefraktor (Nidek, Italy) $30 \mathrm{~min}$ after application of cyclopentolate $1 \%$ eye drops.

\section{Statistical analysis}

Statistical analysis was done with Sigma Plot 12.0 (Systat Software GmbH Erkrath, Germany). One way-analysis of variance was applied to test for significant differences among the different ROP groups and term-born controls. Multiple comparison tests (Holm-Sidak or Dunn's method) were applied when testing for statistical differences between the groups and sectors (BW, GA or STG). Statistical significance was assumed at $\mathrm{p}<0.05$. Pearson product moment correlation was applied when analysing the linear dependence between VA and central LIS.

\section{RESULTS}

\section{Patient statistics}

The analysis presented here is based on the examination of 180 school-aged children (aged 6-13 years, mean 9.2 years). 
A

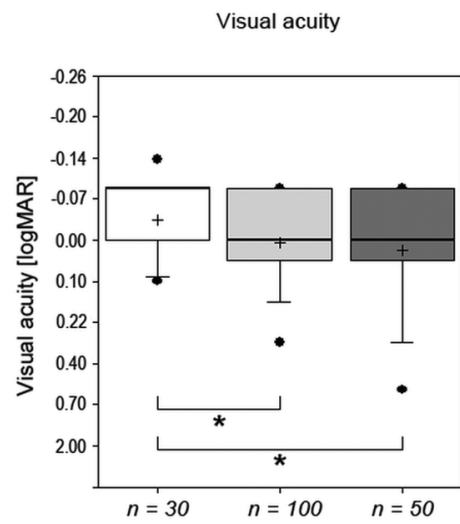

C

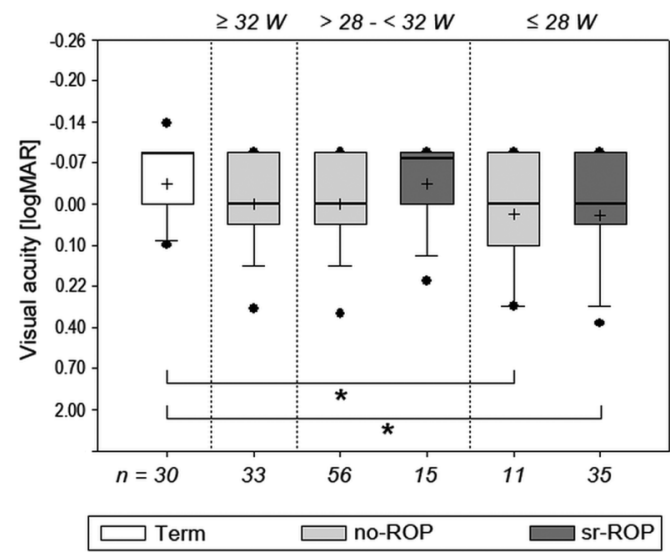

B

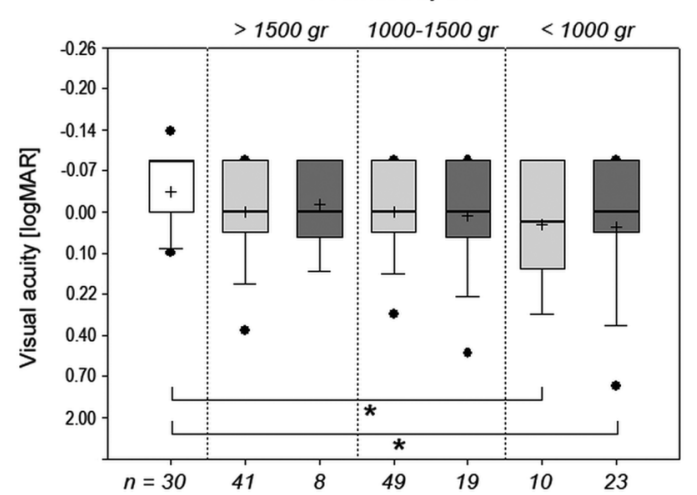

D

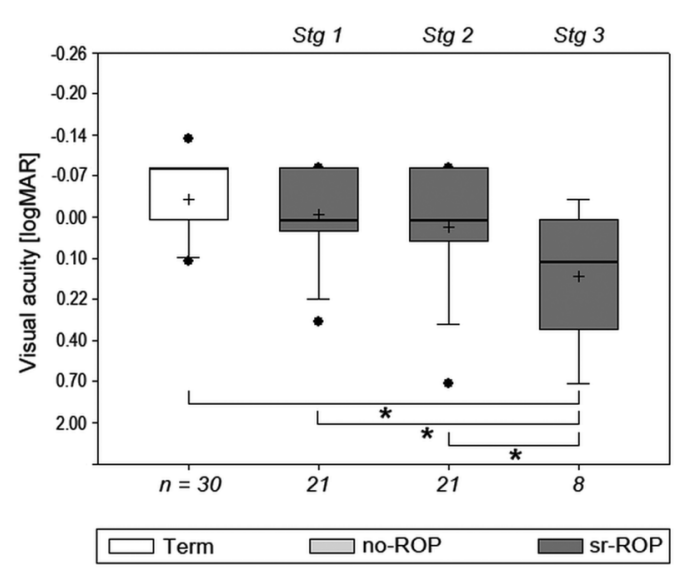

Figure 3 Visual acuity (VA) data. (A) VA data for the entire groups compared with term-born children. (B) VA data for the different study groups in relation to birth weight (BW). (C) VA data for the three different study groups relation to gestational age (GA). (D) VA data for the three study groups in relation to stages of retinopathy of prematurity (ROP). Significant correlations are marked ( ${ }^{*}$ corresponds to $\left.p<0.05\right)$, all other combinations corresponds to $p>0.05$. no-ROP, spontaneously resolved retinopathy of prematurity; sr-ROP, spontaneously resolved retinopathy of prematurity; Term, term-born children.

Children born prematurely were grouped by the results of the ROP screening at 32 weeks of postmenstrual age and subsequent follow-up examinations into children without apparent ROP (no-ROP; $\mathrm{n}=100$ ) and those with spontaneously resolved ROP (sr-ROP; $n=50)$. The group sr-ROP was further divided into subgroups according to stages of ROP (Stg 1; Stg 2; Stg 3). Of the 50 children, maximum stage 1 ROP was detected in 21 children (zone II: $n=16$; zone III: $n=5$ ), another 21 children had stage 2 ROP (zone II: $n=17$; zone III: $\mathrm{n}=4$ ) and 8 children had stage 3 ROP (zone II: $n=7$; zone III: $\mathrm{n}=1$; no plus). All children from both groups were also further divided into sectors according to BW $(>1500 \mathrm{~g}, 1000$ $1500 \mathrm{~g},<1000 \mathrm{~g})$ and GA ( $\geq 32$ weeks, $>28$ to $<32$ weeks, $\leq 28$ weeks).

Demographic data of the enrolled participants are shown in table 1. Both groups, no-ROP and sr-ROP, showed significant differences among each other concerning mean $\mathrm{BW}$ and mean GA, which is in accordance with the higher risk for developing any kind of ROP at low BW and low GA. Spherical equivalent refraction only slightly differed between the no-ROP and sr-ROP group.

\section{Light increment sensitivity}

All children completed the examination procedure of funduscontrolled perimetry with both Goldmann III and Goldmann I stimuli. When comparing LIS depending on eccentricity between the three groups, we found that the foveal LIS $\left(0^{\circ}\right)$ was significantly lower in the no-ROP and sr-ROP-group compared with the term group (figure 1B). Likewise, the parafoveal LIS $\left(2.8^{\circ}\right)$ showed significant differences between the sr-ROP group compared with the term group. No significant differences were found at $8^{\circ}$ between any of the investigated groups (figure 1B).

When analysing the impact of BW, central LIS $\left(0^{\circ}\right)$ was significantly lower for all subjects within the sectors $<1000 \mathrm{~g}$ and 1000 $1500 \mathrm{~g}$, but was unchanged for all subjects in the sector $>1500 \mathrm{~g}$ compared with term-born children (figure 1C). Pericentral LIS $\left(2.8^{\circ}\right)$ was significantly lower for all subjects within the sectors $<1000 \mathrm{~g}$ and $1000-1500 \mathrm{~g}$, but was unchanged for the no-ROP group in the sector 1000-1500 g and all subjects in the sector $>1500 \mathrm{~g}$ compared with term-born children (figure 1D). The peripheral LIS $\left(8^{\circ}\right)$ remained stable und showed no significant change to the term group (data not shown).

Concerning the impact of age, participants in the $\leq 28$ weeks sector had significantly reduced LIS compared with term-born children at $0^{\circ}$ and $2.8^{\circ}$ (figure $1 \mathrm{E}, \mathrm{F}$ ).

The impact of the ROP stage on LIS is shown in figure 2. LIS at $0^{\circ}$ and $2.8^{\circ}$ was significantly reduced in all subgroups compared with the term-born children. Interestingly, the Stg 3 subgroup was significantly reduced compared with both Stg 1 and Stg 2 subgroups at $0^{\circ}$ and significantly reduced compared with Stg 2 subgroup at $2.8^{\circ}$. 


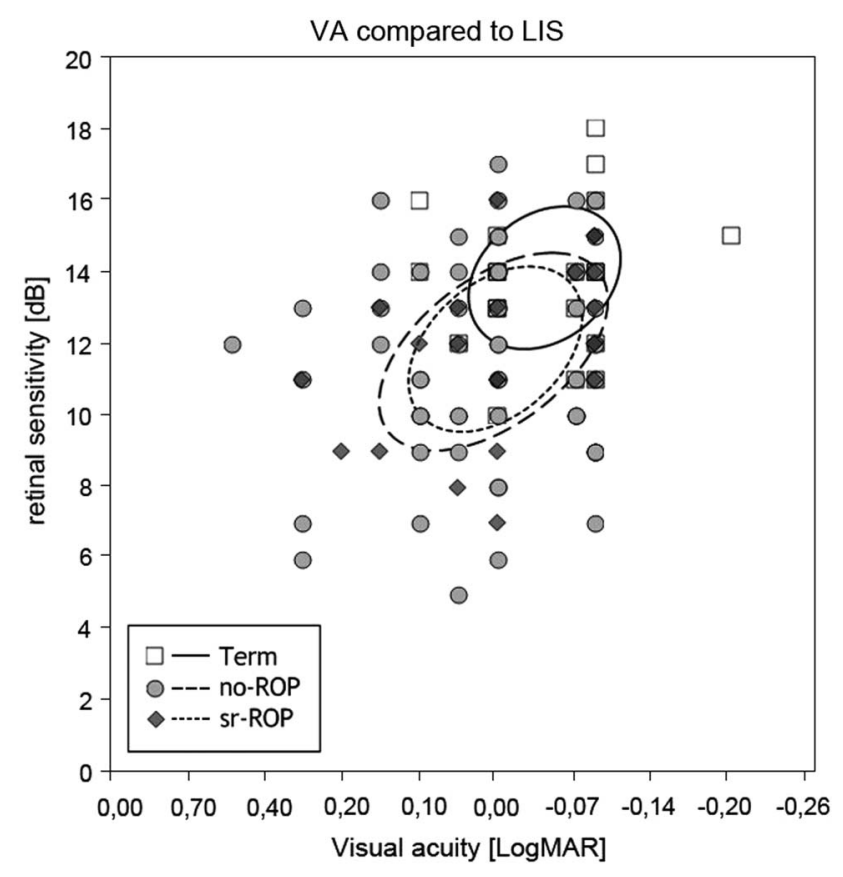

Figure 4 Correlation of visual acuity (VA) and light increment sensitivity (LIS) data on an individual basis. Data of all participants are shown in a scatter plot with $95 \%$ confidence ellipse for the different study groups. Pearson's $r$ for every group was $<0.05$, indicating that no linear correlation exists between VA and central sensitivity (LIS). logMAR, logarithm of the minimum angle of resolution; no-ROP, spontaneously resolved retinopathy of prematurity; sr-ROP, spontaneously resolved retinopathy of prematurity; Term, term-born children.

\section{Visual acuity}

VA was found to be significantly reduced in both groups (no-ROP and sr-ROP) compared with term-born children (figure 3A), but did not differ significantly among each other.

When analysing the impact of GA and BW, VA was significantly lower in the sectors $<1000 \mathrm{~g}$ and $\leq 28$ weeks compared with term-born children (figure 3B, C).

Multiple comparison analysis among the groups (no-ROP, sr-ROP, term) and sectors (BW and GA) revealed for the sectors $<1000 \mathrm{~g} \mathrm{BW}$ and $\leq 28$ weeks GA that the affiliation to a certain ROP group did not result in significant differences in VA. Only the comparison against term-born children was significant.

The analysis of the dependence of stage of ROP on VA is shown in figure 3D. The VA in the Stg 3 subgroup was significantly reduced compared with the term-born children and the Stg 1 and 2 subgroups.

\section{Correlation of central LIS and VA}

Because central LIS and VA data both were reduced with increasing immaturity of the infant and severity of ROP compared with term-born children, we analysed whether these data correlated also on an individual basis (figure 4). We could not detect a significant relationship for participants in any group.

\section{DISCUSSION}

This paper describes the results of LIS and VA in former premature infants compared with term-born children at the age of 613 years. For the first time, we show LIS data correlated with BW and GA at birth, and in relation to the severity of ROP as verified by digital wide-field fundus imaging, and compare these results with VA data. The two data sets revealed matching information concerning the overall reduced function of foveal photoreceptors in very premature children.

VA data of former premature infants obtained in a large number of studies are considered to be the standard parameter to describe foveal function. ${ }^{15-24}$ However, with the recent growth of data describing morphological alterations, such as delayed or incomplete foveal development, arrest of centrifugal inner retinal layer migration or sparing of photoreceptor development, VA data alone may not be sufficient to allow in-depth functional-morphological correlations. ${ }^{40}$ Therefore, our LIS data at $0^{\circ}$ further describe foveal function in addition to VA, and LIS at $2.8^{\circ}$ and $8^{\circ}$ enlarge the functional data set to parafoveal and more peripheral locations.

Interestingly, the foveal and parafoveal LIS ( 0 and $2.8^{\circ}$ ), but not the peripheral LIS $\left(8^{\circ}\right)$, were slightly but significantly reduced in former prematures compared with term-born children. The sectors with the lowest BW or the lowest GA displayed significantly reduced LIS for all groups compared with term-born children, indicating that both factors are the most critical parameters in the development of foveal function. On the other hand, the reduction of LIS in these two sectors with lowest BW or GA was not correlated with the severity of ROP, indicating that ROP stages are only an additional parameter in the development of foveal function.

Peripheral $\left(8^{\circ}\right)$ LIS was not altered in former preterm infants in our study, which may indicate that the immaturity of the retina is restricted to the foveal pit, with normal peripheral retinal function. Detailed analysis of early and follow-up retinal imaging data may help get further insight and is part of ongoing investigations. The value of information on retinal function close to the fovea has been demonstrated in other disorders, where small and locally limited pathologies remained undetected when testing VA alone. ${ }^{36} 37$

The VA data of our study show a general reduction of foveal function in prematurely born children compared with the control group. The reduction increased with the severity of acute ROP. These results are in line with previous populationbased studies. Holmström and colleagues reported a prevalence of poor vision of $34 \%$ for a VA of $<20 / 28$ in the no-ROP group and $61 \%$ in the group with ROP at 4.5 years, and an increased risk for visual dysfunction in children with a history of ROP at 10 years. ${ }^{19}$ In a study with 24 former premature infants, Bonotto and colleagues reported a VA of 20/20 in $87 \%$ for sr-ROP and $100 \%$ for no-ROP. ${ }^{41}$ Furthermore, Villegas and colleagues observed that only $64 \%(n=28)$ of 44 former premature infants had 20/40 VA or better at the age of 2-18 years. ${ }^{40}$

All these data and ours show that prematurity by itself is a risk factor for reduced VA and the presence of ROP increases the risk for poor vision. However, when looking at the two sectors lowest BW and lowest GA, no significant differences were observed between the groups sr-ROP and no-ROP, indicating that, similarly to the LIS data at $0^{\circ}$, BW and GA are the most critical parameters for the determination of highly precise foveal function, and the presence of spontaneously resolving ROP is only a minor parameter in this regard.

Interestingly, while the observed correlations were true for the entire groups, individual results did not show an evident correlation between central LIS $\left(0^{\circ}\right)$ and VA. VA defines the capacity of the central visual system to discriminate contrast variation and is different from LIS, which defines the capacity to discriminate a light stimulus from the background. ${ }^{42}$ Maximum LIS depends on the location of the retina that is tested. Since we 
used bright mesopic conditions and a Goldmann I stimulus at $0^{\circ}$ eccentricity, the detected LIS represents the cone visual system, similar to VA. An indication of the reason of the reduced LIS compared with term-born infants could be differences in morphology on SD-OCT suggestive of photoreceptor immaturity in premature infants. ${ }^{34}$ Correlation of LIS and VA has been performed with varying degrees of success in a number of pathologies, including diabetic macular oedema, idiopathic epimacular membrane or idiopathic macular telangiectasia. ${ }^{3743-45}$ However, since all of these studies used the Goldmann III stimulus, ceiling effects during the tests cannot be excluded, ${ }^{36}$ rendering a comparison with our data difficult. Nonetheless, since both techniques, LIS and VA, describe different qualities of photoreceptor function in the fovea, lack of a direct correlation may not be surprising but opens the range for more functional entities that can be described. For example, a study on factors affecting the reading speed in patients with diabetic macular oedema found that this speed was reduced in those patients treated with laser photocoagulation and correlated significantly with decreased central LIS values and reduced contrast sensitivity, but not VA. ${ }^{46}$

Our results suggest that foveal function is impaired in children with a history of low BW and/or GA at birth, regardless of the development of an acute ROP. The severity of ROP should be considered as an additional factor that may worsen the visual outcome. We postulate that delayed foveal maturation may be an important factor for the development of optimal central visual function and LIS.

Contributors BL and MA-D designed the study. WB, KH, SS, CF and MA-D conducted the study and collected data. KS, WB, KH, SS and BL interpreted the data. KS, WB and BL drafted the work and revised it.

Competing interests None declared.

Patient consent Informed consent was obtained from all parents and informed assent from all children participating in the study.

Ethics approval The present study followed the tenets of the Declaration of Helsinki and was approved by the Ethics Committee of the Justus-Liebig-University of Giessen (Az 150/09).

Provenance and peer review Not commissioned; externally peer reviewed.

\section{REFERENCES}

1 Lundgren P, Kistner A, Andersson EM, et al. Low birth weight is a risk factor for severe retinopathy of prematurity depending on gestational age. PLOS ONE 2014;9: e109460.

2 Maldonado RS, O'Connell RV, Sarin N, et al. Dynamics of human foveal development after premature birth. Ophthalmology 2011;118:2315-25.

3 Dubis AM, Subramaniam CD, Godara P, et al. Subclinical macular findings in infants screened for retinopathy of prematurity with spectral-domain optical coherence tomography. Ophthalmology 2013;120:1665-71.

4 O'Brien KM. Development of the foveal specialization. In: Tombran-Tink J, Barnstable CJ, eds. Visual transduction and non-visual light perception. Humana Press, 2008:17-33.

5 Hendrickson $A E$, Youdelis $C$. The morphological development of the human fovea. Ophthalmology 1984;91:603-12.

6 Youdelis C, Hendrickson AE. A qualitative and quantitative analysis of the human fovea during development. Vision Res 1986;26:847-55.

7 Mann IC. The development of the human eye. 3rd edn. Grune and Stratton, 1964.

8 Vajzovic L, Hendrickson A, O'Connel RV, et al. Maturation of the human fovea: correlation of spectral-domain optical coherence tomography findings with histology. Am J Ophthalmol 2012;154:779-89.

9 Hack M, Fanaroff A. Outcomes of children of extremely low birthweight and gestational age in the 1990's. Early Hum Dev 1999;53:193-218.

10 Austeng D, Källen KB, Ewald UW, et al. Incidence of retinopathy of prematurity in infants born before 27 weeks' gestation in Sweden. Arch Ophthalmol 2009:127:1315-19.

11 Darlow BA, Hutchinson JL, Henderson-Smart DJ, et al. Prenatal risk factors for severe retinopathy of prematurity among very preterm infants of the Australian and New Zealand Neonatal Network. Pediatrics 2005;115:990-6.

12 The Committee for the Classification of Retinopathy of Prematurity. An international classification of retinopathy of prematurity. Arch Ophthalmol 1984;102:1130-4.
13 The Committee for the Classification of Retinopathy of Prematurity. The international classification of retinopathy of prematurity revisited. Arch Ophthalmol 2005; 123:991-9.

14 Good WV. Final results of the early treatment for retinopathy of prematurity (ETROP) randomized trail. Trans Am Ophthalmol Soc 2004;102:1684-94.

15 Holmström G, Azazi M, Jacobson L, et al. A population based, prospective study of the development of ROP in prematurely born children in the Stockholm area of Sweden. Br J Ophthalmol 1993:77:417-23.

16 Holmström G, Azazi M, Kugelberg U. Ophthalmological long term follow up of preterm infants : a population based, prospective study of the refraction and its development. Br J Ophthalmol 1998;82:1265-71.

17 Holmström G, el Azazi M, Kugelberg U. Ophthalmological follow up of preterm infants: a population based, prospective study of visual acuity and strabismus. $\mathrm{Br} J$ Ophthalmol 1999;83:143-50

18 Larsson EK, Rydberg AC, Holmström GE. A population-based study of the refractive outcome in 10-year-old preterm and full-term children. Arch Ophthalmol 2003:121:1430-6.

19 Holmström G, Larsson E. Long-term follow-up of visual functions in prematurely born children-a prospective population-based study up to 10 years of age. J AAPOS 2008;12:157-62.

20 Cryotherapy for Retinopathy of Prematurity Cooperative Group. Multicenter trial of cryotherapy for retinopathy of prematurity: ophthalmological outcomes at 10 years. Arch Ophthalmol 2001;119:1110-18.

21 Cryotherapy for Retinopathy of Prematurity Cooperative Group. Multicenter trial of cryotherapy for retinopathy of prematurity: natural history ROP: ocular outcome at 5 (1/2) years in premature infants with birth weights less than $1251 \mathrm{~g}$. Arch Ophthalmol 2002;120:595-9.

22 Dobson V, Quinn GE, Summers, CG, et al., The Early treatment for Retinopathy of Prematurity Cooperative Group. Grating visual acuity results in the early treatment for retinopathy of prematurity study. Arch Ophthalmol 2011:129:840-6.

23 Good WV, Hardy RJ, Dobson V, et al., The Early treatment for Retinopathy of Prematurity Cooperative Group. Final visual acuity results in the early treatment for retinopathy of prematurity study. Arch Ophthalmol 2010; 128:663-71.

24 Quinn GE, Dobson V, Davitt BV, et al. Progression of myopia and high myopia in the early treatment for retinopathy of prematurity study: findings at 4 to 6 years of age. J AAPOS 2013;17:124-8.

25 Fledelius HC, Bangsgaard R, Slidsborg C, et al. Refraction and visual acuity in a national Danish cohort of 4-year-old children of extremely preterm delivery. Acta Ophthalmol 2015;93:330-8.

26 Fledelius HC. Pre-term delivery and subsequent ocular development. A 7-10 year follow-up of children screened 1982-84 for ROP. Visual function, slit-lamp findings, and fundus appearance. Acta Ophthalmol Scand 1996;74:288-93.

27 Holmström G, Larsson E. Outcome of retinopahty of prematurity. Clin Perinatol 2013:40:311-21

28 Mutlu FM, Küçükevcilioğlu M, Ceylan OM. Risk factor analysis for long-term unfavorable ocular outcomes in children treated for retinopathy of prematurity. Turk J Ped 2013;55:35-41.

29 Darlow BA, Clemett RS, Horwood LJ, et al. Prospective study of New Zealand infants with birth weight less than $1500 \mathrm{~g}$ and screened for retinopathy of prematurity : visual outcome at age 7-8 years. British J Ophthalmol 1997:81:935-40.

30 O'Connor AR, Stephenson T, Johnson A, et al. Long-term ophtalmic outcome of low birth weight children with and without retinopathy of prematurity. Pediatrics 2002;109:12-18.

31 Wang J, Ren $X$, Shen $L$, et al. Development of refractive error in individual children with regressed retinopathy of prematurity. Invest Ophthalmol Vis Sci 2013:54:6018-24.

32 McLoone $E$, O'Keefe M, McLoone $S$, et al. Long term functional and structural outcomes of laser therapy for retinopathy of prematurity. Br J Ophthalmol 2006;90:754-9.

33 Sahni J, Subhedar NV, Clark D. Treated threshold stage 3 versus spontaneously regressed subthreshold stage 3 retinopathy of prematurity: a study of motility, refractive, and anatomical outcomes at 6 months and 36 months. $\mathrm{Br} J$ Ophthalmol 2005:89:154-60.

34 Vajzovic L, Rothman AL, Tran-Viet D, et al. Delay in retinal photoreceptor development in very preterm compared to term infants. Invest Ophthalmol Vis Sci 2015;56:908-13

35 Maldonado RS, Toth CA. Optical coherence tomography in retinopathy of prematurity: looking beyond the vessels. Clin Perinatol 2013;40:271-96.

36 Bowl W, Lorenz $B$, Jäger $M$, et al. Improving detection of mild loss of retinal light increment sensitivity at the posterior pole with the microperimeter MP1. Invest Ophthalmol Vis Sci 2013:54:4666-74.

37 Charbel Issa P, Helb H-M, Rohrschneider K, et al. Microperimetric assessment of patients with type 2 idiopathic macular telangiectasia. Invest Ophthalmol Vis Sci 2007:48:3788-95. 


\section{Clinical science}

38 Lorenz B, Spasovska K, Elflein H, et al. Wide-field digital imaging based telemedicine for screening for acute retinopathy of prematurity (ROP). Six-year results of a multicentre field study. Graefes Arch Clin Exp Ophthalmol 2009;247:1251-62.

39 Klein $\mathrm{R}$, Klein BE, Moss SE, et al. Inter-observer variation in refraction and visual acuity measurement using a standardized protocol. Ophthalmology 1983;90:1357-9.

40 Villegas VM, Capó H, Cavuoto K, et al. Foveal structure-function correlation in children with history of retinopathy of prematurity. Am J Ophthalmol 2014;158:508-12.e2.

41 Bonotto LB, Moreira ATR, Chuffi $S$, et al. Comparative study of visual functions in premature pre-school children with and without retinopathy of prematurity. Arq Bras Oftalmol 2014;77:34-9.
42 Rohrschneider K, Bültmann S, Springer C. Use of fundus perimetry (microperimetry) to quantify macular sensitivity. Prog Retin Eye Res 2008;27:536-48.

43 Okada K, Yamamoto S, Mizunoya S, et al. Correlation of retinal sensitivity measured with microperimetry to visual acuity and retinal thickness in eyes with diabetic macular edema. Eye (Lond) 2006;20:805-9.

44 Carpineto $\mathrm{P}$, Ciancaglini M, Di Antonio L, et al. Fundus microperimetry patterns of fixation in type 2 diabetic patients with diffuse macular edema. Retina 2007;27:21-9.

45 Karacorlu M, Ozdemir H, Senturk F, et al. Correlation of retinal sensitivity with visual acuity and macular thickness in eyes with idiopathic epimacular membrane. Int Ophthalmol 2010;30:285-90.

46 Pearce E, Sivaprasad S, Chong NV. Factors affecting reading speed in patients with diabetic macular edema treated with laser photocoagulation. PLOS ONE 2014;9: e105696. 